\title{
Origem e distribuição dos nervos isquiáticos em caprinos da raça Saanen
}

\author{
Origin and distribution of the ischiatic nerves in goats of the Saanen breed
}

\author{
Eduardo Maurício Mendes de Lima ${ }^{{ }^{*}}$ Frederico Ozanam Carneiro e Silva ${ }^{\text {II }}$ Renato Souto Severino ${ }^{\text {II }}$ \\ Sérgio Salazar Drummond ${ }^{\mathrm{II}}$ Danila Barreiro Campos ${ }^{\mathrm{III}}$ Marcelo Ismar Silva Santana ${ }^{\mathrm{IV}}$ \\ Daniella Dianese Alves de Moraes ${ }^{\mathrm{I}}$
}

\section{RESUMO}

Estudaram-se a origem e distribuição dos nervos isquiáticos, de ambos os antímeros, em 30 caprinos (Capra hircus) da raça Saanen, sendo 16 machos e 14 fêmeas. Estes animais foram coletados após morte natural e submetidos à fixação em solução aquosa, a 10\%, de formaldeído. Os nervos isquiáticos originaram-se 28 vezes $(93,3 \%)$ do ramo ventral do sexto nervo espinhal lombar e dos ramos ventrais do primeiro e segundo nervos espinhais sacrais; além disso, esses nervos tabém receberam duas vezes $(6,7 \%)$, contribuição do ramo ventral do terceiro nervo espinhal sacral. Os nervos isquiáticos cederam, em todos os animais, ramos para os músculos glúteos médios, glúteos profundos, gluteobíceps, gêmeos, semitendíneos e semimembranáceos. Sobretudo, notaram-se arranjos peculiares desses ramos musculares para cada espécime. Através da aplicação da prova de Wilcoxon, com nível de significância de 0,05, não se observaram diferenças significativas entre as freqüencias de ramos musculares dos nervos isquiáticos, que foram cedidos para os antímeros direito e esquerdo, e ainda em relação ao sexo dos caprinos da presente investigação.

Palavras-chave: Capra hircus, Saanen, nervos isquiáticos.

\section{ABSTRACT}

The origin and distribution of the ischiatic nerves at both sides were studied in 30 goats (Capra hircus) of the Saanen breed, being 16 males and 14 females. These specimens were collected after natural death of the animals and submitted to fixation in a $10 \%$ formaldehyde solution. The ischiatic nerves arose from the ventral branch of the sixth lumbar and the first and second sacral spinal nerves in 28 cases (93.3\%). In addition, these nerves also received contributions from the ventral branch of the third sacral spinal nerve in two cases (6.7\%) at both sides. In all animals, the right and left ischiatic nerves gave off branches to the muscles gluteus medius, gluteus profundus, gluteobiceps, gemelli, semitendinosus, and semimembranosus muscles. In particular, peculiar arrangements of these muscular branches were noticed for each specimen. By using the Wilcoxon test with significance level at 0.05, there were no significant differences among the frequencies of muscular branches of the ischiatic nerves emitted to the right and left sides, and also in relation to the sex of the goats in the present investigation.

Key words: Capra hircus, Saanen, ischiatic nerves.

\section{INTRODUÇÃO}

Considerando a importância anatomoclínica do nervo isquiático, COX et al. (1975) comentaram que lesões neste resultaram em paralisia parcial junto à musculatura caudal da coxa em bovinos. Para LAHUNTA \& HABEL (1986), possíveis causas de injúrias ao nervo isquiático em ruminantes decorreram de fraturas da sétima vértebra lombar, luxação sacro-ilíaca, fratura de sacro, fratura do corpo do ílio na altura da incisura isquiática maior, injeções glúteas maldirecionadas, pinos intramedulares proximais no fêmur mal direcionados, fratura do fêmur e injeções maldirecionadas na face caudal da coxa. Em consonância, MOLENAAR (1997) relatou, em

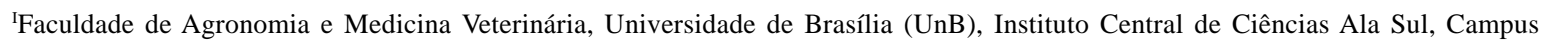
Universitário Darcy Ribeiro, CP 4508, 70910-970, Brasília, DF, Brasil. E-mail: limaemm@unb.br. *Autor para correspondência. "Faculdade de Medicina Veterinária, Universidade Federal de Uberlândia (UFU), Uberlândia, MG, Brasil.

IIIFaculdade de Medicina Veterinária e Zootecnia, Universidade Federal de Uberlândia (USP), São Paulo, SP, Brasil.

${ }^{\text {Iv} P o n t i f i ́ c i a ~ U n i v e r s i d a d e ~ C a t o ́ l i c a ~ d e ~ M i n a s ~ G e r a i s, ~ P o c ̧ o s ~ d e ~ C a l d a s, ~ M G, ~ B r a s i l . ~}$ 
ruminantes, que um feto muito grande ou malposicionado por ocasião do nascimento pode lesar o nervo isquiático de sua mãe, comprometendo então as suas articulações do joelho, bem como aquelas que compõem o seu pé.

Notadamente à formação dos nervos isquiáticos nos ruminantes, SCHWARZE \& SCHRÖDER(1970), GHOSHAL \& GETTY $(1970,1971)$, SISSON \& GROSSMAN (1975), BRUNI \& ZIMMERL (1977), NICKEL et al. (1981), GHOSHAL (1986), GODINHO et al. (1987) e MOLENAAR (1997) aludiram que os referidos nervos apresentaram variadas origens, isto em relação aos ramos ventrais dos últimos nervos espinhais lombares e primeiros sacrais. Mais especificamente, em bovinos azebuados, CAMPOS et al. (2003) citaram que os referidos nervos isquiáticos originaram-se do ramo ventral do quinto e do sexto nervo espinhal lombar e dos ramos ventrais do primeiro, segundo e terceiro nervos espinhais sacrais. De outra forma, FERRAZ et al. (2006), também em fetos de bovinos azebuados, evidenciaram o nervo isquiático tendo sua origem do quinto e sexto nervos lombares e do primeiro e segundo nervos sacrais (100\%).

No tocante aos grupos musculares inervados pelo nervo isquiático, foi mencionado por SCHWARZE \& SCHRÖDER (1970), GHOSHAL \& GETTY (1970, 1971), COX et al. (1975), SISSON \& GROSSMAN (1975), BRUNI \& ZIMMERL (1977), NICKEL et al. (1981), GHOSHAL (1986); GODINHO et al. (1987), MOLENAAR (1997) e CAMPOS et al. (2003) que estes ramos se distribuíram em ruminantes na musculatura dos membros pélvicos. Em seguida, os nervos isquiáticos bifurcaram-se em nervos tibial e fibular comum, distalmente ao trocânter maior do fêmur, de acordo com as citações de SCHWARZE \& SCHRÖDER(1970), GODINHO et al. (1987) e CAMPOS et al. (2003).

A presente investigação teve como primícia acrescentar à literatura informações, de cunho morfológico, referentes aos nervos isquiáticos de ambos os antímeros. Para tanto, verificaram-se os aspectos concernentes à origem dos aludidos nervos e ainda à sua distribuição, a partir de seus ramos musculares, em caprinos (Capra hircus) da raça Saanen.

\section{MATERIAL E MÉTODOS}

Foram utilizados 30 caprinos da raça Saanen, sendo 16 machos e 14 fêmeas, de aproximadamente um mês de idade, coletados, após morte natural, em núcleos criatórios do município de Uberlândia, MG, Brasil.

A fixação desses animais em solução aquosa, a $10 \%$, de formaldeído ocorreu mediante diferentes pontos de injeções subcutâneas, intramusculares e intracavitárias, bem como por imersão das referidas peças em recipientes com a mesma solução. Em seguida, para o conhecimento das origens dos nervos isquiáticos direito e esquerdo, promoveuse uma incisão horizontal ao nível da linha mediana ventral, desde o processo xifóide do osso esterno, até a borda caudal da sínfise pélvica, e, a partir desta, duas outras verticais foram efetuadas, uma em cada antímero, até se alcançar a linha mediana dorsal. Em seguida, promoveu-se a desarticulação da sínfise pélvica, através de secção longitudinal, atingindo-se, por conseguinte, a cavidade pélvica, da qual foram retirados todos os seus órgãos. Deste modo, foi possível a visualização dos ramos ventrais dos nervos espinhais lombares e sacrais de ambos os antímeros, que deram origem aos nervos isquiáticos direito e esquerdo.

Para análise das distribuições dos ramos musculares dos nervos isquiáticos, que foram aqueles emergentes ao longo de cada tronco nervoso em seu respectivo antímero, efetuou-se uma incisão circular na pele do terço médio da perna e outra vertical na pele da face medial da coxa, estendendo-a desde a raiz do membro pélvico até a primeira incisão na perna. Em seqüência, foram contornadas a raiz da cauda, o ânus e os órgãos genitais externos, sendo então rebatidos dorsalmente todo o segmento da pele, bem como as fáscias subcutâneas relativas às regiões glútea, da coxa e da perna.

Tendo como intuito a visualização dos ramos musculares derivados dos nervos isquiáticos, foi seccionado transversalmente, na sua porção distal, e rebatido proximalmente o músculo gluteobíceps, ao nível do trocânter maior do osso fêmur de cada antímero. Em seguida, tiveram isolados e incindidos transversalmente em seus terços médios os músculos glúteos médios e acessórios direito e esquerdo. Com isso, identificaram-se os ramos musculares dos nervos isquiáticos em ambos os antímeros, sendo emitidos ao longo de seus trajetos.

Para comprovação dos resultados, foram elaborados desenhos esquemáticos (Figura 1), alusivos aos ramos ventrais dos nervos espinhais, lombares e sacrais, que originaram os nervos isquiáticos direito e esquerdo. Além disso, foi confeccionada fotografia (Figura 2) representativa da distribuição dos ramos musculares dos nervos isquiáticos, em ambos os antímeros.

A nomenclatura adotada para este estudo esteve de acordo com o preconizado pelo INTERNATIONAL COMMITTEE ON VETERINARY GROSS ANATOMICAL NOMENCLATURE (2005). 


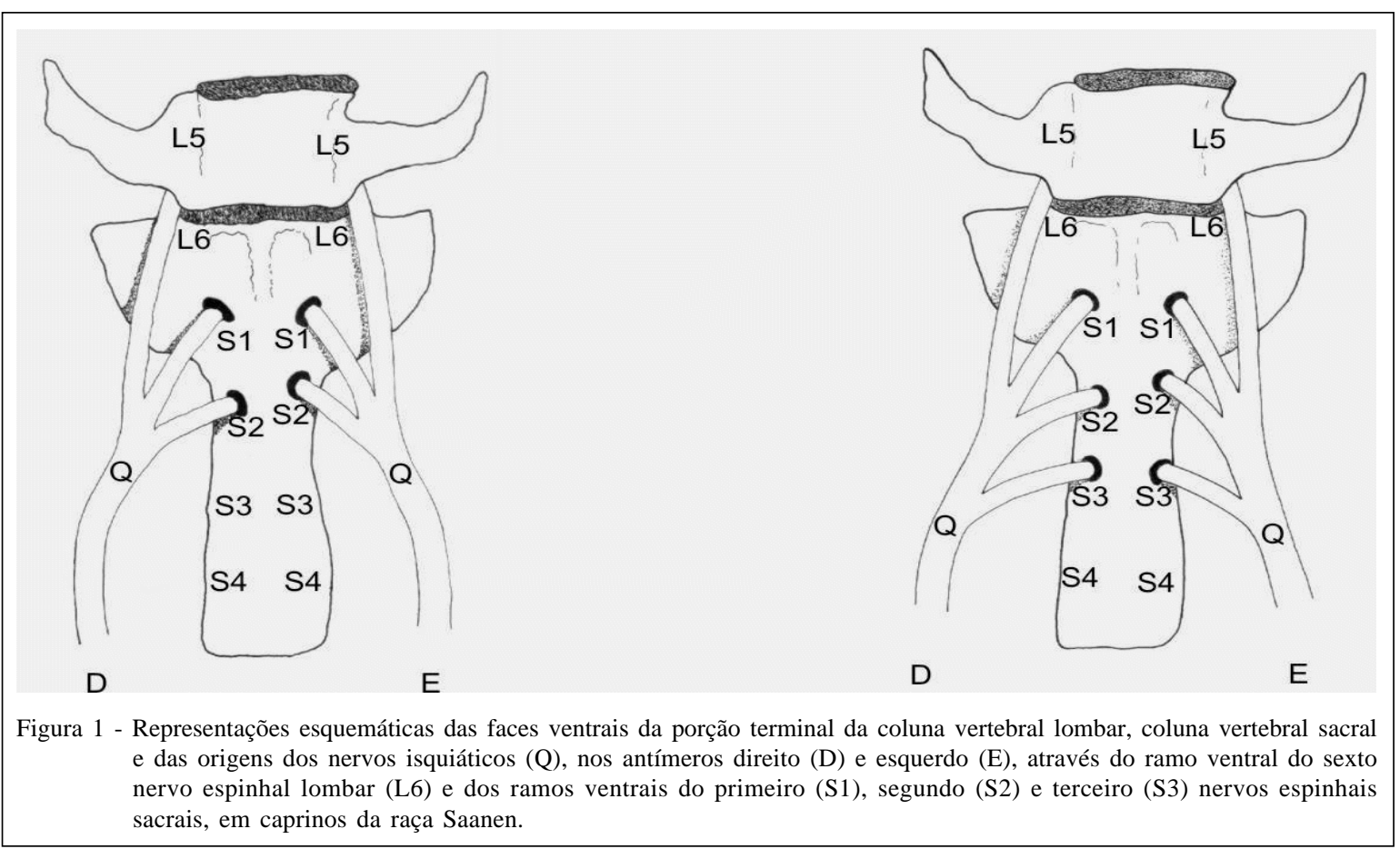

Aplicou-se, como tratamento estatístico, a prova de Wilcoxon (SIEGEL, 1975), com nível de significância de 0,05 , em uma prova bilateral. A partir desta, verificou-se a possível existência de diferenças significativas entre as freqüências de ramos musculares que se destinaram para os músculos glúteo médio, glúteo profundo, gluteobíceps, gêmeo, semitendíneo e semimembranáceo de cada antímero. Ainda, através da mesma prova estatística, observou-se a possível existência de diferenças significativas entre as freqüências de ramos musculares dos nervos isquiáticos, de ambos os antímeros, em relação ao sexo dos animais estudados.

\section{RESULTADOS E DISCUSSÃO}

As informações acerca do conhecimento de particularidades, especialmente no que tange às origens e distribuições dos nervos isquiáticos em caprinos, mostraram-se incipientes de acordo com a literatura consultada.

De acordo com as alusões genéricas de SCHWARZE \& SCHRÖDER (1970), GHOSHAL \& GETTY (1970 e 1971), SISSON \& GROSSMAN (1975), BRUNI \& ZIMMERL (1977), NICKEL et al. (1981), GHOSHAL (1986), GODINHO et al. (1987) e MOLENAAR (1997), os nervos isquiáticos em ruminantes tiveram suas origens do último nervo espinhal lombar e ainda dos primeiros nervos espinhais sacrais. Já no presente estudo, verificou-se que os nervos isquiáticos, em ambos os antímeros, originaramse 28 vezes (93,3\%) especificamente do ramo ventral do último nervo espinhal lombar e dos ramos ventrais do primeiro e segundo nervos espinhais sacrais, em caprinos da raça Saanen.

Nos informes de CAMPOS et al. (2003) para fetos de bovinos azebuados, os nervos isquiáticos originaram-se 19 vezes (63,33\%) do ramo ventral do sexto nervo espinhal lombar e dos ramos ventrais do primeiro e segundo nervos espinhais sacrais; em seis vezes (20\%) receberam, além destas, contribuições do ramo ventral do terceiro nervo espinhal sacral, e, em cinco vezes (16,67\%), do ramo ventral do quinto nervo espinhal lombar. Já de acordo com FERRAZ et al. (2006), o nervo isquiático em bovinos azebuados teve sua origem do quinto e sexto nervos lombares e do primeiro e segundo nervos sacrais (100\%). Em 39,4\% desses casos, o nervo recebeu contribuição do quinto nervo lombar e, em 12,1\% dos casos, recebeu a contribuição do terceiro nervo sacral. A participação mais conspícua na formação do nervo isquiático, em bovinos azebuados, foi a do sexto nervo lombar e do primeiro nervo sacral $(39,4 \%)$, seguida somente do primeiro nervo sacral, em 33,33\%, e da associação do primeiro e segundo nervos sacrais, em 18,18\% (FERRAZ et al., 2006). De outra forma, os achados nos caprinos ora estudados foram de encontro aos informes de CAMPOS et al. (2003) e FERRAZ et al. (2006), em fetos 


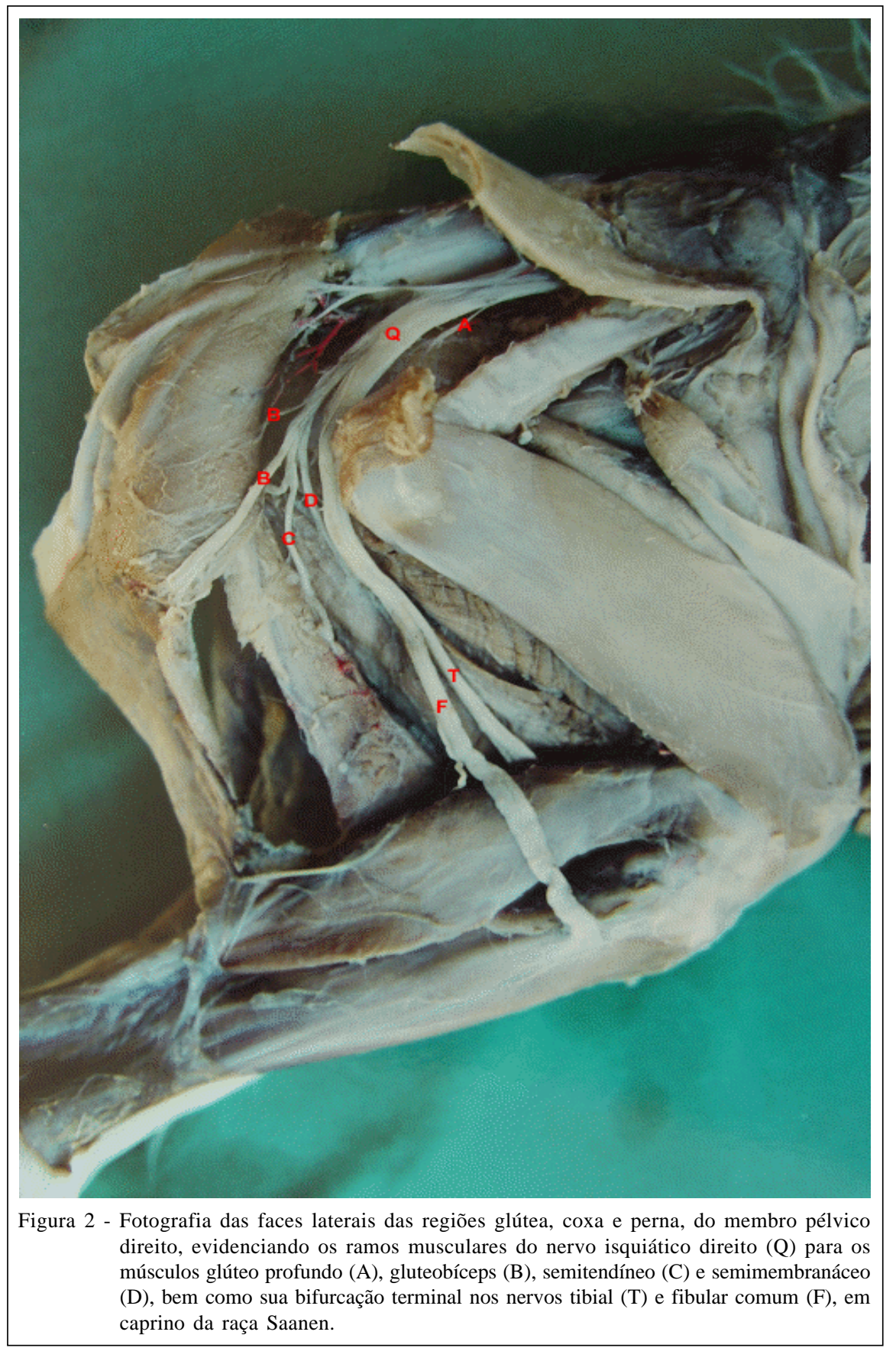

de bovinos azebuados. Entretanto, nos caprinos da raça Saanen, os nervos isquiáticos originaram-se duas vezes $(6,7 \%)$ pelo ramo ventral do sexto nervo espinhal lombar e ainda pelos ramos ventrais do primeiro, segundo e terceiro nervos espinhais sacrais (Figura 1), fato este que coincidiu com as alusões de FERRAZ et al. (2006) para fetos de bovinos azebuados.

No tocante à sua distribuição, constatouse que, ao longo de seu trajeto, os nervos isquiáticos cedendo ramos musculares para os músculos glúteos médios, glúteos profundos, gluteobíceps, gêmeos, semitendíneos e semimembranáceos, de ambos os antímeros (Figura 2). Esses ramos musculares foram aqueles que emergiram ao longo dos nervos isquiáticos, mas não interferiram nos arranjos destes. Foram evidenciados ainda aspectos peculiares na distribuição dos ramos musculares em cada um dos espécimes (Tabela 1).

No condizente à distribuição dos ramos musculares dos nervos isquiáticos nos antímeros direito 
Tabela 1 - Frequência relativa (\%) do número de ramos musculares emitidos pelo nervo isquiático para os músculos do antímero direito (D) e esquerdo (E) em caprinos da raça Saanen, Brasília, DF, Brasil, 2007.

\begin{tabular}{|c|c|c|c|c|c|c|c|c|}
\hline \multirow{3}{*}{ Músculos } & \multicolumn{8}{|c|}{ Número de ramos (\%) } \\
\hline & \multicolumn{2}{|c|}{1} & \multicolumn{2}{|c|}{2} & \multicolumn{2}{|c|}{3} & \multicolumn{2}{|c|}{4} \\
\hline & $\mathrm{D}$ & $\mathrm{E}$ & $\mathrm{D}$ & $\mathrm{E}$ & $\mathrm{D}$ & $\mathrm{E}$ & $\mathrm{D}$ & $\mathrm{E}$ \\
\hline Glúteo médio & 53,3 & 70 & 3,3 & 3,3 & - & - & - & - \\
\hline Glúteo profundo & 30 & 23,3 & 50 & 70 & 16,7 & 6,7 & - & - \\
\hline Gluteobíceps & 3,3 & - & 20 & 53,3 & 70 & 53,3 & 6,7 & 10 \\
\hline Gêmeo & 90 & 93,3 & 6,7 & 3,3 & - & - & - & - \\
\hline Semitendíneo & - & 20 & 63,3 & 73,3 & 3,3 & 6,7 & - & - \\
\hline Semimembranáceo & - & - & 53,3 & 60 & 46,7 & 40 & - & - \\
\hline
\end{tabular}

e esquerdo, COX et al. (1975), BRUNI \& ZIMMERL (1977) e CAMPOS et al. (2003), respectivamente em bovinos, ruminantes e fetos de bovinos azebuados, mencionaram que os referidos nervos e seus ramos supriram os músculos das regiões glútea e da coxa. Este fato foi de encontro aos achados nos caprinos ora estudados, o que caracteriza a sintopia estabelecida pelo referido nervo ao longo de seu trajeto com a musculatura das citadas regiões.

Em se tratando dos ramos dos nervos isquiáticos para os músculos gêmeos, os mesmos foram citados genericamente em ruminantes por SCHWARZE \& SCHRÖDER (1970), GHOSHAL \& GETTY (1970 e 1971), BRUNI \& ZIMMERL (1977), NICKEL et al. (1981), GODINHO et al.(1987), MOLENAAR(1997)eCAMPOS et al. (2003). Da mesma forma, observaram-se, nos animais deste estudo, a presença destes ramos musculares para os antímeros direito e esquerdo (Tabela 1). Concordando com GHOSHAL \& GETTY (1970 e 1971), em caprinos e ovinos, respectivamente, e ainda com CAMPOS et al. (2003), em fetos de bovinos azebuados, os animais desta investigação apresentaram os nervos isquiáticos, de ambos os antímeros, emitindo ramos para os músculos glúteos médios e profundos (Tabela 1).

Como constatado por GHOSHAL \& GETTY (1970 e 1971), em caprinos e ovinos, GHOSHAL (1986), em ruminantes, GODINHO et al. (1987), em ruminantes, e CAMPOS et al. (2003), em fetos de bovinos azebuados e, da mesma forma, em caprinos da raça Saanen (Figura 2), evidenciaram-se, neste trabalho, os músculos gluteobíceps, semitendíneos e semimembranáceos sendo supridos por ramos dos nervos isquiáticos direito e esquerdo (Tabela 1).

Para GHOSHAL \& GETTY (1970 e 1971), em caprinos e ovinos, e ainda, para SISSON \& GROSSMAN (1975), BRUNI \& ZIMMERL (1977), GODINHO et al. (1987) e MOLENAAR (1997), de maneira genérica em rumiantes, estiveram presentes ramos dos nervos isquiáticos, em ambos os antímeros, para os músculos obturatórios interno e externo, quadrado femoral e adutor. Em contrapartida, no material ora trabalhado, não foram evidenciados esses ramos musculares, ressaltando-se, desta forma, a diversidade de músculos supridos por ramos do referido nervo.

No que tange aos nervos tibial e fibular comum, nos caprinos desta investigação, estes caracterizaram-se como sendo os ramos terminais dos nervos isquiáticos, que tiveram suas origens distalmente ao trocânter maior do fêmur, em ambos os antímeros (Figura 2). Esses resultados concordam assim com as alusões de SCHWARZE \& SCHRÖDER (1970), GHOSHAL (1986), GODINHO et al. (1987), genericamente para ruminantes, e CAMPOS et al. (2003), para fetos de bovinos azebuados.

Através da aplicação da prova de Wilcoxon, com nível de significância de 0,05, em uma prova bilateral, não foram evidenciadas diferenças significativas entre as freqüências de ramos musculares colaterais dos nervos isquiáticos, que foram cedidos para os antímeros direito e esquerdo, bem como em relação ao sexo dos caprinos da presente investigação. Assim, esses resultados diferem dos achados de CAMPOS et al. (2003), para fetos de bovinos azebuados, segundo os quais foi observado que as freqüências de ramos cedidos para os músculos de cada antímero diferem em relação ao sexo, de acordo com o teste de Mann-Whitney. Ainda CAMPOS et al. (2003), em fetos de bovinos azebuados, encontraram diferença significativa entre a freqüência de ramos dos nervos isquiáticos emitidos para o músculo glúteo médio direito, em machos e fêmeas.

\section{CONCLUSÃO}

Pautando-se nos achados em caprinos da raça Saanen, evidenciaram-se os nervos isquiáticos, 
em ambos os antímeros, originando-se 28 vezes (93,3\%) através do ramo ventral do sexto nervo espinhal lombar e dos ramos ventrais do primeiro e segundo nervos espinhais sacrais, sendo que, em duas vezes (6,67\%), houve contribuições do ramo ventral do terceiro nervo espinhal sacral. Ao longo de seu trajeto, os nervos isquiáticos, em cada antímero, cederam ramos musculares para a musculatura glútea e da coxa, terminando por bifurcarem-se em nervos tibial e fibular comum, distalmente ao trocânter maior do fêmur. Estatisticamente, não houve diferenças significativas entre as freqüências de ramos musculares colaterais dos nervos isquiáticos, que foram cedidos para os antímeros direito e esquerdo, e ainda destes em relação ao sexo dos animais estudados.

\section{REFERÊNCIAS}

BRUNI, A.C.; ZIMMERL, V. Anatomia degli animali domestici. Milano: Casa Editrici Dr Francesco Vallardi, 1977. 2v. $736 \mathrm{p}$

CAMPOS, D.B. et al. Origem e distribuição dos nervos isquiáticos em fetos de bovinos azebuados. Ars Veterinária, Jaboticabal, v.19, n.3, p-219-223, 2003.

COX, W.S. et al. Surgical and anatomic study of calving paralysis. American Journal of Veterinary Research, Schaumburg, v.36, n.4, p.427-430, 1975.

FERRAZ, R.H.S. et al. Estudo anatômico da porção intrapélvica do nervo isquiático em fetos de bovinos azebuados. Brazilian Journal Veterinary Research and Animal Science, São Paulo, v.43, n.3, p.302-308, 2006.

GHOSHAL, N.G. Nervos espinhais. In: GETTY, R. Sisson/ Grossman anatomia dos animais domésticos. Rio de Janeiro: Guanabara Koogan, 1986. Cap.35, p.1052-1077.
GHOSHAL, N.G.; GETTY, R. The lumbosacral plexus (plexus lumbosacralis) of the goat (Capra hircus). Iowa State Journal Science, Ames, v.2, p.283-296, 1970.

GHOSHAL, N.G.; GETTY, R. The lumbosacral plexus (plexus lumbosacralis) of the sheep (Ovis aries). New Zealand Veterinary Journal, Palmerston North, v.19, n.5, p.85-90, 1971.

GODINHO, H.P. et al. Anatomia dos ruminantes domésticos. Belo Horizonte: Universidade Federal de Minas Gerais, 1987. 438p.

INTERNATIONAL COMMITTEE ON VETERINARY GROSS ANATOMICAL NOMENCLATURE. Nomina anatomica veterinaria. Hannover: Editorial Committee, 2005. 166p.

LAHUNTA, A.; HABEL, R.E. Applied veterinary anatomy. Philadelphia: Saunders, 1986. 142p.

MOLENAAR, G.J. O sistema nervoso. In: DYCE, K.M. et al. Tratado de anatomia veterinária. Rio de Janeiro: Guanabara Koogan, 1997. Cap.08, p.206-257.

NICKEL, R. et al. The locomotor system of the domestic mammals. In: NICKEL, R. et al. The anatomy of the domestic animals. Berlin: Paul Parey, 1981. Cap.04, p.499.

SCHWARZE, E.; SCHRÖDER, L. Sistema nervioso cerebroespinal. In: Compendio de anatomia veterinaria: sistema nervioso y organos de los sentidos. Zaragoza: Acribia, 1970. Cap.4, p.61-90.

SIEGEL, S. Estatística não-paramétrica para as ciências do comportamento. São Paulo: McGraw-Hill do Brasil, 1975. 350p.

SISSON, S.; GROSSMAN, J.D. Sistema nervioso del buey. In: Anatomía de los animales domesticos. Barcelona: Salvat, 1975. Cap.15, p.833-841. 